\title{
Lung function and long-term safety of tiotropium/ olodaterol in East Asian patients with chronic obstructive pulmonary disease
}

This article was published in the following Dove Press journal:

International Journal of COPD

Number of times this article has been viewed

\author{
Chunxue Bai' \\ Masakazu Ichinose ${ }^{2}$ \\ Sang Haak Lee ${ }^{3}$ \\ Kwan Ho Lee ${ }^{4}$ \\ Olaf Jöns ${ }^{5}$ \\ Ulrich Bothner 6 \\ Yihua Zhao ${ }^{7}$ \\ Roland Buhl ${ }^{8}$
}

'Department of Pulmonary Medicine, Shanghai Respiratory Research Institute, Zhongshan Hospital, Fudan University, Shanghai, China; ${ }^{2}$ Department of Respiratory Medicine, Tohoku University Graduate School of Medicine, Sendai, Japan; ${ }^{3}$ Department of Internal Medicine, St Paul's Hospital, College of Medicine, The Catholic University of Korea, Seoul, South Korea; ${ }^{4}$ Department of Internal Medicine, Yeungnam University Medical Center, Daegu, South Korea; ${ }^{5}$ Department of Medicine TA Respiratory Diseases, ${ }^{6}$ Department of Pharmacovigilance, Boehringer Ingelheim Pharma GmbH \& Co. KG, Ingelheim, Germany; ${ }^{7}$ Department of Biostatistics and Data Sciences, Boehringer Ingelheim Pharmaceuticals, Inc., Ridgefield, CT, USA; ${ }^{8}$ Pulmonary Department, Mainz University Hospital, Mainz, Germany

Correspondence: Chunxue Bai Department of Pulmonary Medicine, Shanghai Respiratory Research Institute, Zhongshan Hospital, Fudan University, 180 Feng Lin Road, XuHui District, Shanghai 200032, China

Tel +86 6404 19903077

$\mathrm{Fax}+865496 \quad 1726$

Email bai.chunxue@zs-hospital.sh.cn
Background and purpose: While the efficacy and safety of combined tiotropium and olodaterol in patients with COPD was established in a large clinical trial program, it is important to assess whether clinical data can be applied to geographic patient groups, particularly for East Asian patients who may have a different phenotypic profile to the global trial population. This study aimed to compare the lung function and safety profiles of tiotropium/olodaterol and monocomponents in East Asian and global populations from the TONADO ${ }^{\circledR}$ trials.

Materials and methods: In the replicate, double-blind, parallel-group, active-controlled, randomized, 52-week, Phase III TONADO studies, patients received tiotropium/olodaterol, tiotropium, or olodaterol. We assessed the forced expiratory volume in 1 second $\left(\mathrm{FEV}_{1}\right)$ area under the curve from 0 to 3 hours $\left(\mathrm{AUC}_{0-3}\right)$ response and trough $\mathrm{FEV}_{1}$ response at 24 weeks for the approved doses, tiotropium/olodaterol $5 / 5 \mu \mathrm{g}$, tiotropium $5 \mu \mathrm{g}$, and olodaterol $5 \mu \mathrm{g}$. Treatment-emergent adverse events were recorded throughout treatment and $\leq 21$ days after study medication.

Results: In the East Asian population, 1,152 patients were randomized (5,163 overall). After 24 weeks, $\mathrm{FEV}_{1} \mathrm{AUC}_{0-3}$ and trough $\mathrm{FEV}_{1}$ responses were greater $(P<0.0001)$ with tiotropium/ olodaterol $5 / 5 \mu \mathrm{g}$ in both populations versus tiotropium or olodaterol. The East Asian population showed slightly greater trough $\mathrm{FEV}_{1}$ treatment differences between tiotropium/olodaterol $5 / 5 \mu \mathrm{g}$ and tiotropium compared to the overall population. Generally, no increase in adverse events was seen with tiotropium/olodaterol $5 / 5 \mu \mathrm{g}$ compared to tiotropium and olodaterol in either population.

Conclusion: The efficacy and safety profile of tiotropium/olodaterol $5 / 5 \mu \mathrm{g}$ has been demonstrated for both East Asian and global populations.

Keywords: COPD, adverse effects, pulmonary function, TONADO ${ }^{\circledR}$

\section{Plain language summary}

Why was the study done? Drugs are known to be processed differently in East Asian people compared with Caucasians, which may affect how new therapies perform in this geographic group. We wanted to find out whether a combined treatment for COPD (tiotropium/olodaterol) in East Asian patients works as well and as safely as in the global population.

What did the researchers do and find? We analyzed results from two large identical clinical trials (TONADO ${ }^{\circledR}$ ) in which patients were given either tiotropium/olodaterol $5 / 5 \mu \mathrm{g}$ or the monocomponent tiotropium $5 \mu \mathrm{g}$ or olodaterol $5 \mu \mathrm{g}$ alone, and found that the drugs worked as well and as safely in East Asian patients as in the global population.

What do the results mean? This analysis provides interesting and robust data regarding the East Asian patients included in two large clinical trials of tiotropium/olodaterol for the treatment of COPD. Our findings give reassurance to doctors prescribing tiotropium/olodaterol to patients with COPD that being of East Asian origin should not make a difference on how well tiotropium/olodaterol works and how safe it is. 


\section{Introduction}

COPD is characterized by progressive, persistent airflow limitation, often accompanied by exacerbations and comorbidities. COPD and its accompanying comorbidities remain a leading cause of death worldwide. ${ }^{1}$ The effects of pathophysiologic hallmarks of COPD, such as chronic airflow limitation and hyperinflation, create a need for safe, reliable maintenance therapies.

Long-acting bronchodilators are recommended for maintenance therapy in patients with moderate to very severe COPD. ${ }^{1}$ Tiotropium is an established once-daily, long-acting muscarinic antagonist that has been shown to improve the lung function and patient-reported outcomes such as dyspnea and quality of life, and reduce exacerbations in patients with COPD. ${ }^{2-8}$ Olodaterol is a long-acting $\beta_{2}$-agonist (LABA) that provides 24 -hour bronchodilation and symptomatic benefits in patients with COPD. ${ }^{9-12}$ The advantages of combining tiotropium and olodaterol as a long-acting bronchodilator have been demonstrated in an extensive clinical trial program $\left(\mathrm{TOviTO}^{\circledR}\right),{ }^{13-17}$ and the combination is now available globally at a dose of $5 / 5 \mu \mathrm{g}$ for once-daily use via the Respimat $^{\circledR}$ inhaler (Boehringer Ingelheim, Ingelheim am Rhein, Germany).

Long-term efficacy and safety results of treatment with tiotropium/olodaterol in a global population with moderate to very severe COPD over 52 weeks versus the monocomponents have been published from two replicate Phase III trials (TONADO 1 and 2). ${ }^{13}$ Tiotropium/olodaterol has also been shown to improve the lung function to a greater extent in patients with Global Initiative for Chronic Obstructive Lung Disease (GOLD) 2 compared to GOLD 3-4 disease, stressing the importance of providing early maintenance therapy in patients with COPD. ${ }^{18}$

There is a concern that global clinical trial data may not be applicable to East Asian patients due to lower average body weight and potentially different metabolism and elimination profiles, compared to a predominantly Caucasian population..$^{19}$ For example, in the PHILO trial of the blood thinner ticagrelor, Asian patients had notably worsened outcomes compared to other ethnic populations. ${ }^{20}$ In cancer patients, the incidence of severe neutropenia following treatment with the chemotherapy drug docetaxel was demonstrated to be 19 times greater than in non-Asian patients in Phase II and III clinical trials, ${ }^{21}$ leading to the proposal of dose reduction in Asian patients treated with docetaxel. ${ }^{22}$ A $10 \%$ dose reduction in Asian patients with head and neck squamous cell cancer receiving induction chemotherapy with dose-modified docetaxel, cisplatin, and 5-fluorouracil achieved similar survival figures compared to the original recommended dose regimen. ${ }^{23}$ For inhaled drugs, in particular, the response and long-term safety profiles may be different in regional patient populations according to different population characteristics such as phenotype physiology, genetics, disease severity, and distribution of other risk factors in the target COPD population. ${ }^{24,25}$

In the clinical pharmacology programs for tiotropium/ olodaterol, tiotropium, and olodaterol, there was no observed influence of patient race, ${ }^{13}$ although the lung function benefits and safety were not specifically analyzed in East Asian patients. This paper will describe the lung function and safety profiles of tiotropium/olodaterol and the monocomponents in the East Asian population from the large TONADO studies compared to the overall population.

\section{Materials and methods Study design}

The detailed methodology of TONADO has been previously published. ${ }^{13}$ Briefly, this trial was a pair of replicate, doubleblind, parallel-group, active-controlled, multicenter, randomized, Phase III studies (registered with ClinicalTrials.gov: NCT01431274 [Study 1237.5] and NCT01431287 [Study 1237.6]). Eligible patients were $\geq 40$ years of age with a diagnosis of COPD, a smoking history of $>10$ pack-years, post-bronchodilator forced expiratory volume in 1 second $\left(\mathrm{FEV}_{1}\right)<80 \%$ of predicted normal, and post-bronchodilator $\mathrm{FEV}_{1}$ /forced vital capacity (FVC) $<70 \%$.

Patients received tiotropium/olodaterol $2.5 / 5 \mu \mathrm{g}$ or $5 / 5 \mu \mathrm{g}$, tiotropium 2.5 or $5 \mu \mathrm{g}$, or olodaterol $5 \mu \mathrm{g}$ over 52 weeks. This analysis focused on the approved doses of tiotropium/olodaterol $5 / 5 \mu \mathrm{g}$, tiotropium $5 \mu \mathrm{g}$, and olodaterol $5 \mu \mathrm{g}$, which are the worldwide marketed product doses of tiotropium/olodaterol (Spiolto ${ }^{\circledR}$ Respimat), tiotropium (Spiriva ${ }^{\circledR}$ Respimat), and olodaterol (Striverdi ${ }^{\circledR}$ Respimat) in COPD. All treatments were administered once daily via the Respimat inhaler. Salbutamol (albuterol) $(100 \mu \mathrm{g}$ per actuation) was provided as rescue medication for all study participants and use was recorded in a diary. All studies were conducted in accordance with the Declaration of Helsinki and the International Conference on Harmonisation's Harmonised Tripartite Guideline for Good Clinical Practice and local regulations. This work observed appropriate ethical guidelines relating to clinical trials involving human participants and with approval from institutional review boards (Coordinating Investigator's [Prof Roland Buhl] Independent Ethics Committee: Ethikkommission bei der Landesärztekammer Rheinland-Pfalz, Deutschhausplatz 3, 
55116 Mainz, Germany). Patients provided written informed consent for this study.

\section{Study outcomes and assessments}

For the overall study, primary end points included $\mathrm{FEV}_{1}$ area under the curve from 0 to 3 hours $\left(\mathrm{AUC}_{0-3}\right)$ response (change from baseline), trough $\mathrm{FEV}_{1}$ response, and St George's Respiratory Questionnaire (SGRQ) total score, all measured at 24 weeks. Secondary end points included a Transition Dyspnea Index focal score, also measured at 24 weeks, and further end points included $\mathrm{FEV}_{1}$ response over time measured at 5 minutes post-dose on Day 1 and at Weeks 12, 24, and 52. These and others have been reported elsewhere. ${ }^{13}$

\section{Subgroup analysis}

The East Asian population was selected by Asian race from countries of mainland China, Taiwan, Japan, and South Korea; India was not included in countries defining the East Asian population. The overall population was defined as all patients worldwide, including the East Asian population.

In this prespecified exploratory analysis, we only report lung function end points $\left(\mathrm{FEV}_{1} \mathrm{AUC}_{0-3}\right.$, trough $\mathrm{FEV}_{1}$, and FVC), SGRQ total score, and safety. Transition Dyspnea Index focal score data, which was also exploratory in nature, are not included. $P$-values associated with treatment comparisons for the East Asian population were non-alpha controlled. $P$-values associated with treatment comparisons for the primary and key secondary end points for the overall population were confirmatory.

Treatment-emergent adverse events (AEs) were recorded, regardless of causality, throughout the trial and during a follow-up period of 21 days after study medication discontinuation. Vital signs were recorded at screening, baseline, and after 12, 24, and 52 weeks of treatment, and measured before the pre-dose and 60-minute post-dose pulmonary function tests. Twelve-lead electrocardiogram recordings were performed at screening, study withdrawal, pre-dose, and 40 minutes post-dose at baseline and at Weeks 12, 24 , and 52.

Serious AEs were reviewed by an independent external expert adjudication committee, which was blinded to treatment, to determine if any of the deaths, hospitalizations, or intubations were related to respiratory, cardiovascular, cerebrovascular, or other diseases.

All randomized patients who received at least one dose of treatment were included in the safety analysis set (treated set). The frequencies of investigator-reported AEs (coded using the Medical Dictionary for Regulatory Activities) were analyzed descriptively. Analyses were performed on pooled data from the TONADO studies and were based on treatment-emergent AEs, including those AEs that occurred after the first dose of trial medication and within 21 days after the last dose of trial medication.

\section{Results}

\section{Patients}

A total of 6,887 patients were enrolled in the study across 40 different countries. ${ }^{13}$ In the overall population, 5, $163(75.0 \%)$ patients were randomized to receive treatment, with $84.6 \%$ of patients completing the trials and $15.4 \%$ prematurely discontinuing study medication. In this article, we report on a total of 3,100 patients in the two studies, who were treated with tiotropium/olodaterol $5 / 5 \mu \mathrm{g}(1,029 ; 33.2 \%)$, tiotropium $5 \mu \mathrm{g}(1,033 ; 33.3 \%)$, or olodaterol $5 \mu \mathrm{g}(1,038$; $33.5 \%)$. Of these, $2,175(70.2 \%)$ patients classified their race as white, 807 (26.0\%) as Asian, 40 (1.3\%) as black/African American, and $20(0.6 \%)$ as American Indian/Alaska Native. Information on race could not be collected for $58(1.9 \%)$ patients. Regionally, the overall population was divided between Western Europe (26.9\%), East Asia (22.9\%), North America (19.5\%), Eastern Europe (16.3\%), Latin America $(8.9 \%)$, India (3.0\%), and Australia/New Zealand/South Africa (2.5\%).

In the East Asian population, 1,525 patients were enrolled, with $1,152(75.5 \%)$ randomized to receive treatment. Of these, 1,151 patients received treatment. The trial was completed by $89.2 \%$ of patients, while $10.8 \%$ prematurely discontinued. For this analysis, a total of $709(22.9 \%)$ patients were treated with the marketed product doses of tiotropium/olodaterol $5 / 5 \mu \mathrm{g}$, tiotropium $5 \mu \mathrm{g}$, or olodaterol $5 \mu \mathrm{g}$. The distribution of treatments was similar to the overall population, with $228(32.2 \%)$ patients receiving tiotropium/ olodaterol $5 / 5 \mu \mathrm{g}, 243(34.3 \%)$ receiving tiotropium $5 \mu \mathrm{g}$, and $238(33.6 \%)$ receiving olodaterol $5 \mu \mathrm{g}$.

Some differences in demographics and baseline information were observed between the East Asian and overall populations (Table 1). The East Asian population contained a higher proportion of men, a lower mean weight and body mass index, and a lower percentage of current smokers than the overall population. The East Asian population reported less usage of pulmonary medication, particularly, inhaled corticosteroids, LABAs, and short-acting $\beta$-agonists, but did show an increased use of xanthines. There were also fewer comorbidities at baseline in the East Asian population and a shorter history of COPD diagnosis. Post-bronchodilator lung function at screening was slightly lower in the East Asian 
Table I Demographic and baseline patient characteristics

\begin{tabular}{|c|c|c|c|c|c|c|}
\hline \multirow[t]{3}{*}{ Demographic/characteristic } & \multicolumn{3}{|c|}{ East Asian population } & \multicolumn{3}{|c|}{ Overall population^ } \\
\hline & $05 \mu \mathrm{g}$ & T $5 \mu \mathrm{g}$ & $\mathrm{T} / O 5 / 5 \mu \mathrm{g}$ & $05 \mu \mathrm{g}$ & T $5 \mu \mathrm{g}$ & $\mathrm{T} / 05 / 5 \mu \mathrm{g}$ \\
\hline & $(n=238)$ & $(n=243)$ & $(n=228)$ & $(n=1,038)$ & $(n=1,033)$ & $(n=I, 029)$ \\
\hline Male, n (\%) & $225(94.5)$ & $234(96.3)$ & $219(96.1)$ & $764(73.6)$ & $755(73.1)$ & $733(71.2)$ \\
\hline Age, years, mean (SD) & $66.2(8.0)$ & $65.7(8.1)$ & $66.2(7.6)$ & $64.2(8.2)$ & $63.9(8.6)$ & $63.8(8.3)$ \\
\hline Weight, kg, mean (SD) & $61.8(11.8)$ & $63.2(10.6)$ & $60.5(10.1)$ & $73.3(18.2)$ & $74.0(17.6)$ & $72.9(17.7)$ \\
\hline Body mass index (kg/m²), mean (SD) & $22.5(3.8)$ & $22.8(3.4)$ & $22.2(3.2)$ & $25.9(5.8)$ & $26.0(5.3)$ & $25.8(5.4)$ \\
\hline Duration of COPD diagnosis, years, mean (SD) & $4.7(5.1)$ & $4.8(5.5)$ & $5.0(5.6)$ & $6.8(6.2)$ & $6.4(6.1)$ & $6.4(5.6)$ \\
\hline \multicolumn{7}{|l|}{ Smoking status, $\mathrm{n}(\%)$} \\
\hline Ex-smoker & $180(75.6)$ & $190(78.2)$ & $176(77.2)$ & $660(63.6)$ & $663(64.2)$ & $629(6 I .1)$ \\
\hline Current smoker & $58(24.4)$ & $53(21.8)$ & $52(22.8)$ & $378(36.4)$ & $370(35.8)$ & $400(38.9)$ \\
\hline \multicolumn{7}{|l|}{ History of COPD diagnosis, $n(\%)$} \\
\hline$<$ I year & $5 \mathrm{I}(2 \mathrm{I} .4)$ & $57(23.5)$ & $42(18.4)$ & II 8 (I I.4) & $140(13.6)$ & $109(10.6)$ \\
\hline I to $<10$ years & $159(66.8)$ & $150(61.7)$ & $157(68.9)$ & $659(63.5)$ & $654(63.3)$ & $680(66.1)$ \\
\hline 10 to $<20$ years & $22(9.2)$ & $30(12.3)$ & $20(8.8)$ & $206(19.8)$ & $199(19.3)$ & $208(20.2)$ \\
\hline$\geq 20$ years & $6(2.5)$ & $6(2.5)$ & $9(3.9)$ & $55(5.3)$ & $40(3.9)$ & $32(3.1)$ \\
\hline Comorbidities, n (\%) & $180(75.6)$ & $186(76.5)$ & $167(73.2)$ & $897(86.4)$ & $902(87.3)$ & $890(86.5)$ \\
\hline Cardiac & $44(18.5)$ & $33(13.6)$ & $30(13.2)$ & $234(22.5)$ & $219(21.2)$ & $213(20.7)$ \\
\hline Vascular & $87(36.6)$ & $102(42.0)$ & $81(35.5)$ & $511(49.2)$ & $513(49.7)$ & $496(48.2)$ \\
\hline Metabolism and nutrition & $59(24.8)$ & $46(18.9)$ & $43(18.9)$ & $370(35.6)$ & $354(34.3)$ & $338(32.8)$ \\
\hline Respiratory, thoracic, and mediastinal & $29(12.2)$ & $34(14.0)$ & $25(11.0)$ & $192(18.5)$ & $213(20.6)$ & $200(19.4)$ \\
\hline \multicolumn{7}{|l|}{ GOLD, n (\%) } \\
\hline $\mathrm{I}(\geq 80 \%)$ & $0(0.0)$ & $0(0.0)$ & $0(0.0)$ & $0(0.0)$ & $I(0.1)$ & $0(0.0)$ \\
\hline $2(50 \%$ to $<80 \%)$ & I I4 (47.9) & $110(45.3)$ & $109(47.8)$ & $532(5 I .3)$ & $517(50.0)$ & $502(48.8)$ \\
\hline $3(30 \%$ to $<50 \%)$ & $89(37.4)$ & $92(37.9)$ & $83(36.4)$ & $378(36.4)$ & $387(37.5)$ & $408(39.7)$ \\
\hline $4(<30 \%)$ & $35(14.7)$ & $41(16.9)$ & $36(15.8)$ & $128(12.3)$ & $128(12.4)$ & $119(11.6)$ \\
\hline SGRQ total score, unadjusted mean (SE)* & $37.0(1.2)$ & $38.7(1.3)$ & $38.6(1.2)$ & $42.8(0.6)$ & $43.3(0.6)$ & $44.2(0.6)$ \\
\hline \multicolumn{7}{|l|}{ Mean (SD) post-bronchodilator } \\
\hline $\mathrm{FEV}_{1}, \mathrm{~L}$ & $\mathrm{I} .29(0.46)$ & $\mathrm{I} .30(0.49)$ & $1.28(0.46)$ & $1.38(0.52)$ & $\mathrm{I} .37(0.52)$ & $\mathrm{I} .34(0.5 \mathrm{I})$ \\
\hline$\%$ Predicted normal & $48.85(15.91)$ & $47.53(16.39)$ & $48.11(15.72)$ & $50.26(15.59)$ & $49.70(15.67)$ & $49.32(15.29)$ \\
\hline \multicolumn{7}{|l|}{ Baseline pulmonary medication, $\mathrm{n}(\%)$} \\
\hline SAMA & $13(5.5)$ & $12(4.9)$ & $8(3.5)$ & $134(12.9)$ & $13 \mid(12.7)$ & $125(12.1)$ \\
\hline LAMA & $85(35.7)$ & $76(31.3)$ & $82(36.0)$ & $365(35.2)$ & $346(33.5)$ & $378(36.7)$ \\
\hline SABA & $23(9.7)$ & $21(8.6)$ & $20(8.8)$ & $424(40.8)$ & $40 \mathrm{I}(38.8)$ & $400(38.9)$ \\
\hline LABA & $65(27.3)$ & $55(22.6)$ & $57(25.0)$ & 49I (47.3) & $450(43.6)$ & $486(47.2)$ \\
\hline ICS & $73(30.7)$ & $69(28.4)$ & $70(30.7)$ & $505(48.7)$ & $466(45.1)$ & $506(49.2)$ \\
\hline Xanthines & $36(15.1)$ & $50(20.6)$ & $41(18.0)$ & $96(9.2)$ & $109(10.6)$ & $108(10.5)$ \\
\hline
\end{tabular}

Notes: *From the full analysis set, East Asian population: $\mathrm{n}=228$ (O $5 \mu \mathrm{g}), \mathrm{n}=233$ (T $5 \mu \mathrm{g}), \mathrm{n}=215$ (T/O 5/5 $\mu \mathrm{g})$; overall population: $\mathrm{n}=954$ (O $5 \mu \mathrm{g}), \mathrm{n}=955$ (T $5 \mu \mathrm{g}), \mathrm{n}=979$

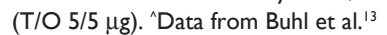

Abbreviations: $\mathrm{FEV}_{1}$, forced expiratory volume in I second; GOLD, Global Initiative for Chronic Obstructive Lung Disease; ICS, inhaled corticosteroid; LABA, long-acting $\beta_{2}$-agonist; LAMA, long-acting muscarinic antagonist; O, olodaterol; SABA, short-acting $\beta$-agonist; SAMA, short-acting muscarinic antagonist; SD, standard deviation; SE, standard error; SGRQ, St George's Respiratory Questionnaire; T, tiotropium.

population, although this population also had slightly more patients with COPD severity of GOLD 4.

\section{Lung function}

After 24 weeks, the adjusted mean $\mathrm{FEV}_{1} \mathrm{AUC}_{0-3}$ and trough $\mathrm{FEV}_{1}$ responses were significantly greater $(P<0.0001)$ with tiotropium/olodaterol $5 / 5 \mu \mathrm{g}$ versus monocomponents in both the East Asian and overall populations (Figure 1A and B). The East Asian population showed slightly greater trough $\mathrm{FEV}_{1}$ treatment differences between tiotropium/ olodaterol $5 / 5 \mu \mathrm{g}$ and tiotropium $5 \mu \mathrm{g}$, when compared to the overall population (Figure 1B).
The secondary end point of the $\mathrm{FVC} \mathrm{AUC}_{0-3}$ response significantly improved $(P<0.05)$ in both the East Asian and overall populations with tiotropium/olodaterol $5 / 5 \mu \mathrm{g}$ versus tiotropium $5 \mu \mathrm{g}$ and olodaterol $5 \mu \mathrm{g}$ (Figure 1C). FEV response over time favored tiotropium/olodaterol $5 / 5 \mu \mathrm{g}$ compared to the monocomponents in both groups, and again treatment differences were larger for the East Asian population compared to the overall population (Figure 2A and B).

\section{Quality of life}

Symptomatic benefit of tiotropium/olodaterol 5/5 $\mu \mathrm{g}$ was demonstrated by statistically significant improvements 

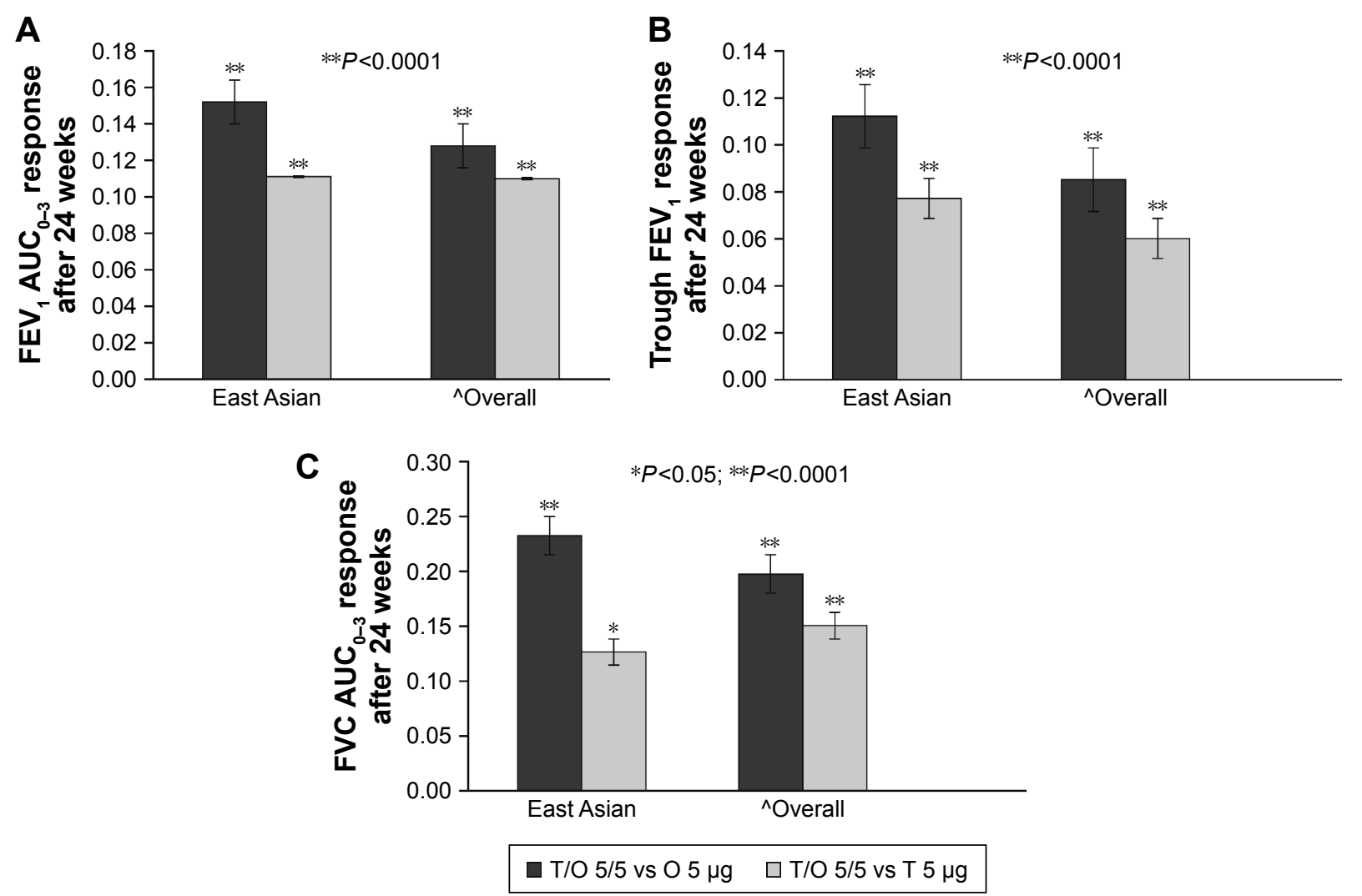

Figure I Treatment differences for (A) FEV $\mathrm{AUC}_{0-3}$ response, (B) trough $\mathrm{FEV}$, response, and (C) FVC AUC $\mathrm{C}_{0-3}$ response after 24 weeks in the East Asian and overall populations.

Note: ^Data from Buhl et al. ${ }^{13}$

Abbreviations: $\mathrm{AUC}_{0-3}$, area under the curve from 0 to 3 hours; $\mathrm{FEV}_{1}$, forced expiratory volume in I second; FVC, forced vital capacity; O, olodaterol; $\mathrm{T}$, tiotropium.

in mean SGRQ total score versus both monotherapies in the overall population after 24 weeks; in the East Asian population, this benefit was observed versus olodaterol $5 \mu \mathrm{g}$ (Table 2).

Similarly, responder rates, which are defined as a reduction of SGRQ total score of $\geq 4$ units from baseline, were significantly greater for tiotropium/olodaterol $5 / 5 \mu \mathrm{g}$ versus both monotherapies in the overall population; in the East Asian population, this was observed versus olodaterol $5 \mu \mathrm{g}$ treatment (Table 3).

\section{Safety}

The incidence of AEs was similar in the East Asian and overall populations and was generally balanced across all treatment groups (Table 4). A similar number of AEs were considered treatment related in the East Asian and overall populations ( $7.1 \%$ versus $6.6 \%$, respectively). The majority of AEs in both populations were mild to moderate in severity, and similar proportions of patients discontinued treatment due to AEs across treatment groups and between populations. In the East Asian population, there was a lower incidence of serious AEs and fatal AEs compared to the overall population, although the numbers were low. The most frequent System Organ Class events reported in both populations were infections and infestations, and respiratory, thoracic, and mediastinal disorders (Figure 3A and B). The East Asian population had a higher incidence of infections and infestations (including upper respiratory tract infections, bronchitis, and pneumonia) and a lower incidence of respiratory, thoracic, and mediastinal disorders (including COPD exacerbation); musculoskeletal and connective tissue disorders (including back pain); and nervous system disorders (including headache) when compared to the overall population.

Incidences of clinically relevant cardiovascular AEs were low in both populations (Table 5). The East Asian population reported slightly lower incidences of tachyarrhythmia and ischemic heart disease than the overall population.

Respiratory AEs in the East Asian and overall populations were broadly comparable between treatment groups (Table 6). The East Asian population had slightly lower incidence of lower respiratory disorders, including COPD exacerbation, compared to the overall population. 


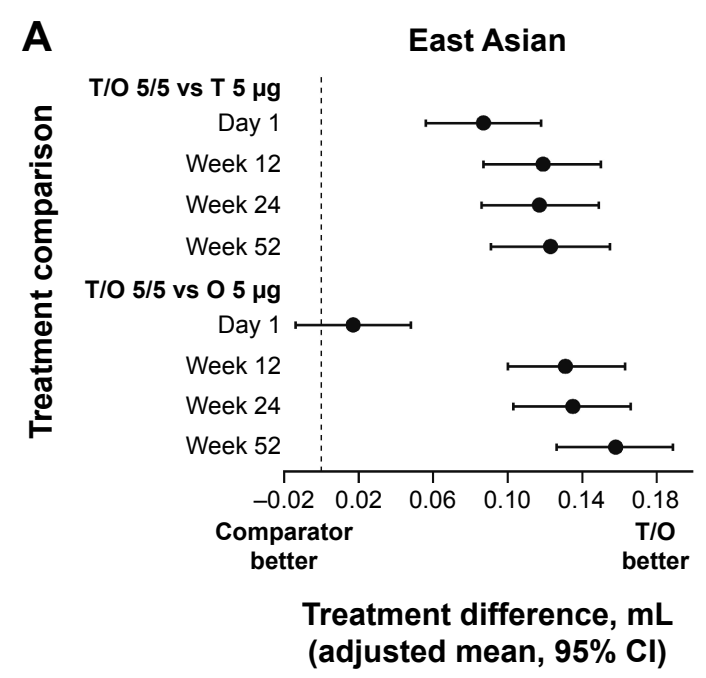

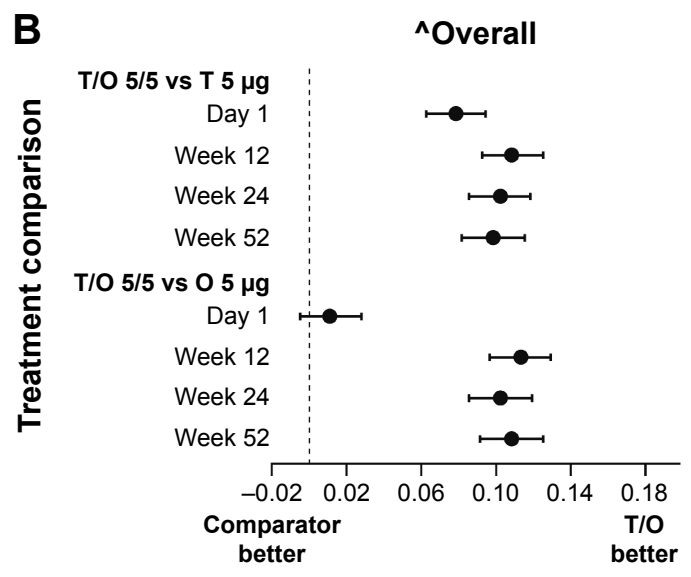

Treatment difference, $\mathrm{mL}$ (adjusted mean, 95\% Cl)

Figure 2 FEV treatment comparisons at 5 minutes post-dose at Day I, Week 12, Week 24, and Week 52: (A) East Asian population and (B) overall population. Note: ^Data from Buhl et al. ${ }^{13}$

Abbreviations: $\mathrm{FEV}_{1}$, forced expiratory volume in I second; $\mathrm{O}$, olodaterol; $\mathrm{T}$, tiotropium.

Table 2 SGRQ score treatment comparison after 24 weeks of treatment

\begin{tabular}{|c|c|c|c|c|}
\hline \multirow{3}{*}{$\begin{array}{l}\text { Treatment } \\
\text { comparison }\end{array}$} & \multicolumn{4}{|c|}{ Treatment difference } \\
\hline & \multicolumn{2}{|l|}{ East Asians } & \multicolumn{2}{|l|}{ `Overall population } \\
\hline & $\begin{array}{l}\text { SGRQ total score, adjusted } \\
\text { mean } \pm \text { SE }(95 \% \mathrm{Cl})\end{array}$ & $P$-value & $\begin{array}{l}\text { SGRQ total score adjusted } \\
\text { mean } \pm \text { SE }(95 \% \mathrm{Cl})\end{array}$ & $P$-value \\
\hline \multicolumn{5}{|l|}{$\mathrm{T} / O 5 / 5 \mu \mathrm{g}$} \\
\hline Versus $\bigcirc 5 \mu \mathrm{g}$ & $-2.519 \pm 1.202(-4.876,-0.162)$ & 0.0362 & $-1.693 \pm 0.553(-2.778,-0.608)$ & 0.0022 \\
\hline Versus T $5 \mu \mathrm{g}$ & $-0.730 \pm 1.180(-3.044,1.583)$ & 0.5358 & $-1.233 \pm 0.55 \mid(-2.313,-0.153)$ & 0.0252 \\
\hline
\end{tabular}

Note: ^Data from Buhl et al. ${ }^{13}$

Abbreviations: O, olodaterol; SE, standard error; SGRQ, St George's Respiratory Questionnaire; T, tiotropium.

Table 3 Responder analysis of SGRQ total score treatment comparisons after 24 weeks of treatment

\begin{tabular}{|c|c|c|c|c|}
\hline \multirow{3}{*}{$\begin{array}{l}\text { Treatment } \\
\text { comparison }\end{array}$} & \multicolumn{4}{|c|}{ Treatment difference } \\
\hline & \multicolumn{2}{|l|}{ East Asians } & \multicolumn{2}{|l|}{ `Overall population } \\
\hline & Odds ratio \pm SE $(95 \% \mathrm{Cl})$ & $P$-value & Odds ratio \pm SE $(95 \% \mathrm{Cl})$ & $P$-value \\
\hline \multicolumn{5}{|l|}{$\mathrm{T} / O 5 / 5 \mu \mathrm{g}$} \\
\hline Versus $\bigcirc 5 \mu \mathrm{g}$ & $1.902 \pm 0.3665(1.303,2.775)$ & 0.0009 & $1.670 \pm 0.153(1.395,1.999)$ & $<0.0001$ \\
\hline Versus T $5 \mu \mathrm{g}$ & $1.169 \pm 0.2220(0.806,1.696)$ & 0.4103 & $1.426 \pm 0.131(1.192,1.706)$ & 0.0001 \\
\hline
\end{tabular}

Note: ^Data from Buhl et al. ${ }^{13}$

Abbreviations: O, olodaterol; SE, standard error; SGRQ, St George's Respiratory Questionnaire; T, tiotropium.

Table 4 Summary of AEs

\begin{tabular}{|c|c|c|c|c|c|c|}
\hline \multirow[t]{3}{*}{ Events } & \multicolumn{3}{|c|}{ East Asian population, $\mathbf{n}(\%)$} & \multicolumn{3}{|c|}{${ }^{\wedge}$ Overall population, $\mathbf{n}(\%)$} \\
\hline & $05 \mu \mathrm{g}$ & T $5 \mu \mathrm{g}$ & $\mathrm{T} / O 5 / 5 \mu \mathrm{g}$ & $05 \mu \mathrm{g}$ & T $5 \mu \mathrm{g}$ & $\mathrm{T} / O 5 / 5 \mu \mathrm{g}$ \\
\hline & $(n=238)$ & $(n=243)$ & $(n=228)$ & $(n=1,038)$ & $(n=I, 033)$ & $(n=1,029)$ \\
\hline All AEs & $182(76.5)$ & $168(69.1)$ & 157 (68.9) & $795(76.6)$ & $757(73.3)$ & $761(74.0)$ \\
\hline Treatment-related AEs & $17(7.1)$ & $15(6.2)$ & $18(7.9)$ & $69(6.6)$ & $63(6.1)$ & $73(7.1)$ \\
\hline Severe AEs & $28(11.8)$ & $20(8.2)$ & $23(10.1)$ & $162(15.6)$ & $145(14.0)$ & $157(15.3)$ \\
\hline AEs leading to discontinuation & $17(7.1)$ & $16(6.6)$ & $15(6.6)$ & $103(9.9)$ & $93(9.0)$ & $76(7.4)$ \\
\hline Serious AEs ${ }^{\mathrm{a}}$ & $42(17.6)$ & $4 I(16.9)$ & $32(14.0)$ & $181(17.4)$ & $172(16.7)$ & $169(16.4)$ \\
\hline Fatal AEs & $\mathrm{I}(0.4)$ & $2(0.8)$ & $3(1.3)$ & $14(1.3)$ & $17(1.6)$ & $18(1.7)$ \\
\hline Life-threatening AEs & $0(0.0)$ & $0(0.0)$ & $0(0.0)$ & $3(0.3)$ & $2(0.2)$ & $5(0.5)$ \\
\hline Disabling/incapacitating & $0(0.0)$ & $0(0.0)$ & $0(0.0)$ & $\mathrm{I}(0.1)$ & $2(0.2)$ & $3(0.3)$ \\
\hline Requiring hospitalization & $40(16.8)$ & $39(16.0)$ & $27(11.8)$ & $162(15.6)$ & $155(15.0)$ & $153(14.9)$ \\
\hline Prolonging hospitalization & $\mathrm{I}(0.4)$ & $0(0.0)$ & $\mathrm{I}(0.4)$ & $12(1.2)$ & $3(0.3)$ & $6(0.6)$ \\
\hline Other & $\mathrm{I}(0.4)$ & $4(1.6)$ & $\mathrm{I}(0.4)$ & 20 (1.9) & $18(1.7)$ & $12(1.2)$ \\
\hline
\end{tabular}

Notes: ${ }^{\wedge}$ Data from Buhl et al..$^{13}$ Percentages are calculated using total number of patients per treatment as the denominator. ${ }^{\mathrm{a}} \mathrm{A}$ patient may be counted in more than one seriousness criterion.

Abbreviations: AEs, adverse events; O, olodaterol; T, tiotropium. 
A

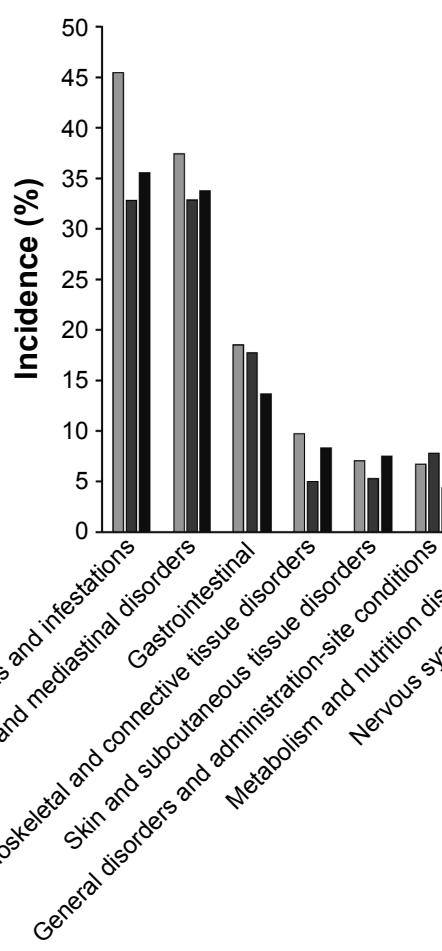

B

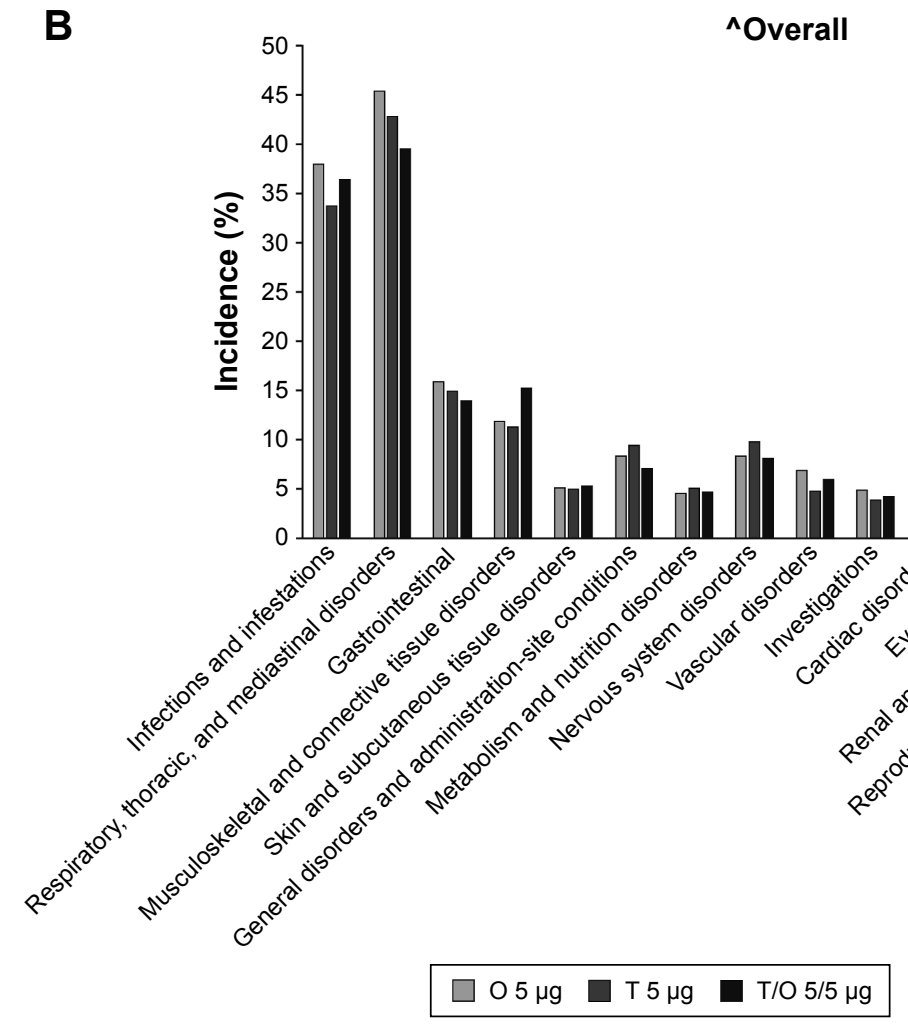

East Asian
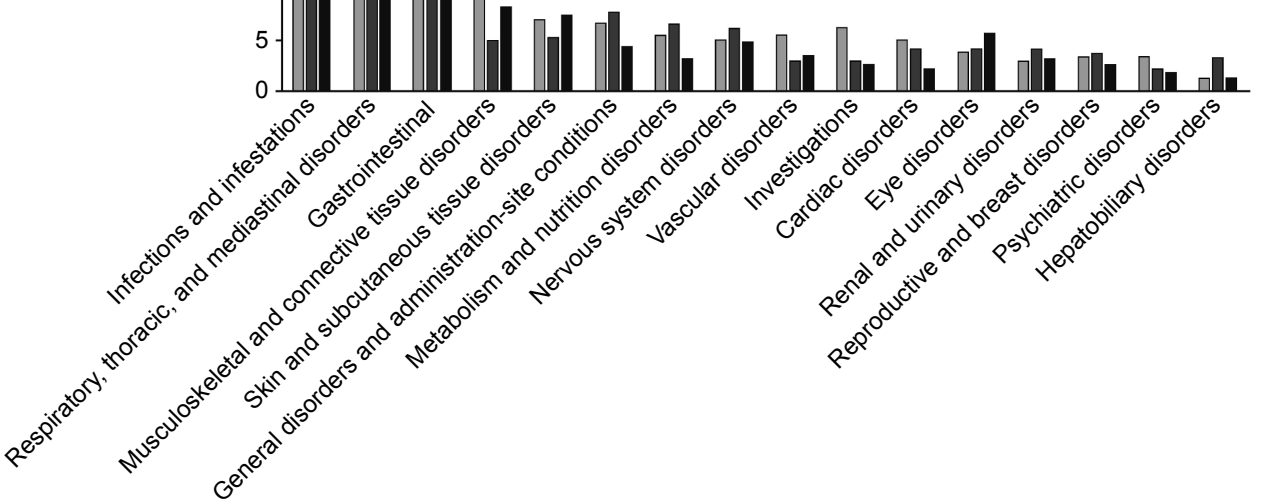

Figure 3 AEs occurring with an incidence of $>3 \%$ by System Organ Class: (A) East Asian population and (B) overall population. Note: 'Data from Buhl et al. ${ }^{13}$

Abbreviations: AEs, adverse events; $\mathrm{O}$, olodaterol; T, tiotropium.

Incidences of upper and lower respiratory tract infections, including bronchitis and pneumonia, were higher in the East Asian population, but comparable among the treatment groups.
There was generally no increase in incidence of AEs, cardiac AEs, or respiratory AEs with tiotropium/olodaterol $5 / 5 \mu \mathrm{g}$ compared to tiotropium $5 \mu \mathrm{g}$ and olodaterol $5 \mu \mathrm{g}$ in either population. 
Table 5 Clinically relevant cardiovascular AEs

\begin{tabular}{|c|c|c|c|c|c|c|}
\hline \multirow[t]{3}{*}{ AE } & \multicolumn{3}{|c|}{ East Asian population, $\mathbf{n}(\%)$} & \multicolumn{3}{|c|}{ `Overall population, n (\%) } \\
\hline & O $5 \mu \mathrm{g}$ & T $5 \mu \mathrm{g}$ & $\mathrm{T} / O 5 / 5 \mu \mathrm{g}$ & $05 \mu \mathrm{g}$ & T $5 \mu \mathrm{g}$ & $\mathrm{T} / O 5 / 5 \mu \mathrm{g}$ \\
\hline & $(n=238)$ & $(n=243)$ & $(n=228)$ & $(n=1,038)$ & $(n=1,033)$ & $(n=1,029)$ \\
\hline Tachyarrhythmia & $4(1.7)$ & $\mathrm{I}(0.4)$ & I $(0.4)$ & $13(1.3)$ & $12(1.2)$ & $14(1.4)$ \\
\hline Supraventricular (including atrial fibrillation) & $\mathrm{I}(0.4)$ & $\mathrm{I}(0.4)$ & $0(0.0)$ & $6(0.6)$ & $8(0.8)$ & $5(0.5)$ \\
\hline Ventricular (including extrasystoles) & $2(0.8)$ & $0(0.0)$ & $0(0.0)$ & $6(0.6)$ & $2(0.2)$ & $6(0.6)$ \\
\hline Ischemic heart disease & $3(1.3)$ & $4(1.6)$ & $4(1.8)$ & $26(2.5)$ & $22(2.1)$ & $22(2.1)$ \\
\hline Myocardial infarction & $\mathrm{I}(0.4)$ & $\mathrm{I}(0.4)$ & $4(1.8)$ & $10(1.0)$ & $8(0.8)$ & $\mathrm{II}(\mathrm{I} . \mathrm{I})$ \\
\hline Other ischemic heart disease & $2(0.8)$ & $4(1.6)$ & $0(0.0)$ & $19(1.8)$ & $16(1.5)$ & $12(1.2)$ \\
\hline MACE & $4(1.7)$ & $5(2.1)$ & $8(3.5)$ & $25(2.4)$ & $19(1.8)$ & $24(2.3)$ \\
\hline Fatal MACE & I (0.4) & I (0.4) & $2(0.9)$ & $8(0.8)$ & $6(0.6)$ & $8(0.8)$ \\
\hline
\end{tabular}

Notes: Percentages are calculated using total number of patients per treatment as the denominator. 'Data from Buhl et al. ${ }^{13}$

Abbreviations: AE, adverse event; MACE, major adverse cardiovascular event; $\mathrm{O}$, olodaterol; $\mathrm{T}$, tiotropium.

\section{Discussion}

As mentioned earlier, differences in efficacy and safety in clinical studies of different therapies have been reported between Asian and non-Asian populations ${ }^{20-23}$ and demonstrate the need to carefully assess all therapies in Asian populations.

This study assessed lung function and safety in a subset of East Asian patients in the large, replicate, 52-week TONADO studies, in comparison with the overall population. Minor differences were found in several population characteristics and baseline demographics, such as sex, weight, and pulmonary medication use at baseline. The East Asian population also had a lower incidence of comorbidities and a lower proportion of current smokers than the overall population. This finding may be due to a higher prevalence of smoking reported in Europe for both men and women, while a very high prevalence of smoking was reported only among men in East Asia. ${ }^{26}$ The sex difference in smoking prevalence in the East Asian population may explain the low number of females included in the East Asian subgroup compared with the overall population. However, this did not seem to impact other demographics such as age or severity of disease, which may be expected as female COPD patients are often older than males or have more severe disease if not differentiated by age. One final difference between populations was the treatments used at baseline. Short-acting muscarinic antagonist, short-acting $\beta$-agonist, inhaled corticosteroid, and LABA were used less frequently in the East Asian population compared with the overall population, while the use of xanthines was higher. As the severity of disease was relatively consistent across the populations as per the GOLD stages, these treatment differences likely reflect differences in clinical practice in East Asia compared with other regions included in the overall population.

Lung function, as measured by $\mathrm{FEV}_{1}$ and $\mathrm{FVC}$ responses, improved substantially with tiotropium/olodaterol $5 / 5 \mu \mathrm{g}$ in the East Asian population compared to monocomponents, which was consistent with the overall population. ${ }^{13}$ No significant differences in safety outcomes were seen between the two populations. Minor differences in clinically relevant cardiovascular outcomes were noted, with the East Asian population reporting lower incidences of tachyarrhythmia and ischemic heart disease; this was possibly influenced

Table 6 Clinically relevant respiratory AEs

\begin{tabular}{|c|c|c|c|c|c|c|}
\hline \multirow[t]{3}{*}{ AE } & \multicolumn{3}{|c|}{ East Asian population, $\mathbf{n}(\%)$} & \multicolumn{3}{|c|}{${ }^{\wedge}$ Overall population, n (\%) } \\
\hline & $05 \mu \mathrm{g}$ & T $5 \mu \mathrm{g}$ & $\mathrm{T} / 05 / 5 \mu \mathrm{g}$ & $05 \mu \mathrm{g}$ & T $5 \mu \mathrm{g}$ & $\mathrm{T} / O 5 / 5 \mu \mathrm{g}$ \\
\hline & $(n=238)$ & $(n=243)$ & $(n=228)$ & $(n=1,038)$ & $(n=1,033)$ & $(n=1,029)$ \\
\hline Respiratory disorders (lower) & $92(38.7)$ & $82(33.7)$ & $78(34.2)$ & $470(45.3)$ & $433(41.9)$ & $403(39.2)$ \\
\hline COPD exacerbation & $78(32.8)$ & $68(28.0)$ & $66(28.9)$ & $403(38.8)$ & $363(35.1)$ & $356(34.6)$ \\
\hline Dyspnea & $5(2.1)$ & $4(1.6)$ & $7(3.1)$ & $39(3.8)$ & $52(5.0)$ & $43(4.2)$ \\
\hline Cough & $8(3.4)$ & $8(3.3)$ & $3(1.3)$ & $43(4.1)$ & 51 (4.9) & $43(4.2)$ \\
\hline Lower respiratory tract infection & $25(10.5)$ & $22(9.1)$ & $29(12.7)$ & $86(8.3)$ & $63(6.1)$ & $68(6.6)$ \\
\hline Bronchitis & $12(5.0)$ & $14(5.8)$ & $18(7.9)$ & $38(3.7)$ & $27(2.6)$ & $34(3.3)$ \\
\hline Pneumonia & $12(5.0)$ & $7(2.9)$ & $13(5.7)$ & $41(3.9)$ & $27(2.6)$ & $36(3.5)$ \\
\hline Upper respiratory tract infection & $29(12.2)$ & $27(11.1)$ & $24(10.5)$ & $56(5.4)$ & $57(5.5)$ & $54(5.2)$ \\
\hline Nasopharyngitis & $35(14.7)$ & $24(9.9)$ & $33(14.5)$ & $131(12.6)$ & 121 (II.7) & $128(12.4)$ \\
\hline
\end{tabular}

Notes: Percentages are calculated using total number of patients per treatment as the denominator. ${ }^{\circ}$ Data from Buhl et al. ${ }^{13}$

Abbreviations: $\mathrm{AE}$, adverse event; $\mathrm{O}$, olodaterol; $\mathrm{T}$, tiotropium. 
by fewer comorbidities and current smokers at baseline in the East Asian population. Minor differences were also seen in clinically relevant respiratory events, with higher incidences for upper respiratory tract infections, bronchitis, and pneumonia seen in East Asian patients.

There was a significant reduction in SGRQ total score and responder rates for tiotropium/olodaterol $5 / 5 \mu \mathrm{g}$ versus monotherapy for the overall population. In the East Asian population, SGRQ improvements were observed versus olodaterol $5 \mu \mathrm{g}$, but not tiotropium $5 \mu \mathrm{g}$. This was an exploratory analysis, and the lower number of East Asian patients included in this study limits the interpretation of this result. It is, however, also worth noting that improvements in SGRQ score from baseline have previously been described in placebo-treated patients from the Asia-Pacific area, which were accredited to a "trial effect", showing sustained improvements irrespective of whether patients were receiving active study treatment. ${ }^{27}$ Participation in a clinical trial in some Asian regions, in particular China, may have led to improved overall health care of patients. This observation should be considered for our findings, where the percentage of responders for treatment with tiotropium monotherapy was slightly raised compared with the overall population $(51.9 \%$ versus $48.7 \%$ ).

Generally, no increase in AEs was seen with tiotropium/ olodaterol $5 / 5 \mu \mathrm{g}$ compared to the monocomponents in either of the populations. These findings reflect the overall safety analysis of the TONADO study. ${ }^{13}$ Interestingly, the incidences of most AE categories were lower for tiotropium/ olodaterol $5 / 5 \mu \mathrm{g}$ compared to monocomponents in both populations (Figure $3 \mathrm{~A}$ and $\mathrm{B}$ ). These data demonstrate that tiotropium/olodaterol $5 / 5 \mu \mathrm{g}$ offers an acceptable safety profile in East Asian populations as well as in the overall population. These data mirror the safety data reported with olodaterol alone, where no safety concerns were identified up to 1 year at doses up to twice the recommended dose in Japanese and other Asian patients compared to Caucasian patients. ${ }^{28}$ Tiotropium $5 \mu \mathrm{g}$ alone has also been shown to significantly improve the lung function and demonstrated an acceptable safety profile in Chinese patients with COPD. ${ }^{29}$

The pattern of AEs seen in the East Asian and overall populations is also likely influenced by comorbidities, which have a high prevalence among patients with COPD. ${ }^{30}$ The most common comorbidities include cardiovascular diseases, metabolic disorders, osteoporosis, skeletal muscle dysfunction, anxiety/depression, cognitive impairment, gastrointestinal diseases, and respiratory conditions, which can have unique effects on COPD management and treatment. ${ }^{31}$ The prevalence of AEs in this study is probably influenced by the presence of abundant comorbidities typically seen in patients with COPD.

This study had some limitations. Due to the high risk for events merely from preexisting comorbidities, it is usually difficult to assess a causal relationship between inhaled medications and AEs in patients with COPD. The East Asian population also contained a smaller number of patients, but the data are reassuring and suggest no obvious concerns for using tiotropium/olodaterol $5 / 5 \mu \mathrm{g}$ in the East Asian population.

Overall, the efficacy/safety profile and positive benefitrisk of tiotropium/olodaterol $5 / 5 \mu \mathrm{g}$, as established for the overall population, have been demonstrated for the East Asian subpopulation. Physicians should feel confident prescribing tiotropium/olodaterol $5 / 5 \mu \mathrm{g}$ to patients in the East Asian population.

\section{Acknowledgments}

The authors received no compensation related to the development of the manuscript. Medical writing assistance was provided by Laura Badtke, $\mathrm{PhD}$, of Complete HealthVizion. This work was supported by Boehringer Ingelheim Pharma $\mathrm{GmbH} \&$ Co. KG. Medical writing assistance was contracted and compensated by Boehringer Ingelheim Pharma GmbH \& Co. KG.

\section{Author contributions}

The authors meet the criteria for authorship as recommended by the International Committee of Medical Journal Editors. They take full responsibility for the scope, direction, content, and editorial decisions relating to the manuscript; were involved at all stages of development; and have approved the submitted manuscript. All authors contributed to the concept/design of the study, data acquisition, or analysis and interpretation of the data. $\mathrm{CB}, \mathrm{OJ}$, and $\mathrm{UB}$ were involved in the analysis and planning for this manuscript; collated the data; and were involved with the interpretation of the study. MI, SHL, and KHL were study investigators and participated in the coordination and interpretation of the study. $\mathrm{YZ}$ performed the statistical analyses and was involved in the interpretation of the study. RB was the coordinating investigator of the study and participated in the design, implementation, and interpretation of the study.

\section{Disclosure}

RB reports grants from Boehringer Ingelheim, Novartis, and Roche, and personal fees from AstraZeneca, Boehringer Ingelheim, Chiesi, Novartis, Roche, GlaxoSmithKline, and 
Takeda. MI reports personal fees from Nippon Boehringer Ingelheim, AstraZeneca, Novartis Pharma KK, and Kyorin. $\mathrm{OJ}$ and UB are employees of Boehringer Ingelheim Pharma $\mathrm{GmbH} \& \mathrm{Co}$. YZ is an employee of Boehringer Ingelheim Pharmaceuticals, Inc. The authors report no other conflicts of interest in this work.

\section{References}

1. Global Initiative for Chronic Obstructive Lung Disease. Global Strategy for the Diagnosis, Management, and Prevention of Chronic Obstructive Pulmonary Disease: 2016 Report. Available from: http://goldcopd. org/global-strategy-diagnosis-management-prevention-copd-2016/. Accessed April 27, 2016.

2. Casaburi R, Mahler DA, Jones PW, et al. A long-term evaluation of once-daily inhaled tiotropium in chronic obstructive pulmonary disease. Eur Respir J. 2002;19(2):217-224.

3. O'Donnell DE, Fluge T, Gerken F, et al. Effects of tiotropium on lung hyperinflation, dyspnoea and exercise tolerance in COPD. Eur Respir J. 2004;23(6):832-840.

4. Maltais F, Hamilton A, Marciniuk D, et al. Improvements in symptomlimited exercise performance over $8 \mathrm{~h}$ with once-daily tiotropium in patients with COPD. Chest. 2005;128(3):1168-1178.

5. Tashkin DP, Celli B, Senn S, et al. A 4-year trial of tiotropium in chronic obstructive pulmonary disease. $N$ Engl J Med. 2008;359(15): 1543-1554.

6. Bateman ED, Tashkin D, Siafakas N, et al. A one-year trial of tiotropium Respimat plus usual therapy in COPD patients. Respir Med. 2010; 104(10): 1460-1472.

7. Yohannes AM, Willgoss TG, Vestbo J. Tiotropium for treatment of stable COPD: a meta-analysis of clinically relevant outcomes. Respir Care. 2011; 56(4):477-487.

8. Vogelmeier C, Hederer B, Glaab T, et al. Tiotropium versus salmeterol for the prevention of exacerbations of COPD. NEngl J Med.2011;364(12): 1093-1103.

9. Ferguson GT, Feldman GJ, Hofbauer P, et al. Efficacy and safety of olodaterol once daily delivered via Respimat ${ }^{\circledR}$ in patients with GOLD 2-4 COPD: results from two replicate 48-week studies. Int J Chron Obstruct Pulmon Dis. 2014;9:629-645.

10. Koch A, Pizzichini E, Hamilton A, et al. Lung function efficacy and symptomatic benefit of olodaterol once daily delivered via Respimat ${ }^{\circledR}$ versus placebo and formoterol twice daily in patients with GOLD 2-4 COPD: results from two replicate 48 -week studies. Int J Chron Obstruct Pulmon Dis. 2014;9:697-714.

11. Feldman GJ, Bernstein JA, Hamilton A, Nivens MC, Korducki L, LaForce C. The 24-h FEV1 time profile of olodaterol once daily via Respimat ${ }^{\mathbb{B}}$ and formoterol twice daily via Aerolizer ${ }^{\circledR}$ in patients with GOLD 2-4 COPD: results from two 6-week crossover studies. Springerplus. 2014;3(1):419.

12. Lange P, Aumann J, Hamilton A, Tetzlaff K, Ting N. The 24-hour lung function time profile of olodaterol once daily versus placebo and tiotropium in patients with moderate to very severe chronic obstructive pulmonary disease. J Pulm Respir Med. 2014;4(4):196.

13. Buhl R, Maltais F, Abrahams R, et al. Tiotropium and olodaterol fixeddose combination versus mono-components in COPD (GOLD 2-4). Eur Respir J. 2015;45(4):969-979.

14. Cazzola M, Rogliani P, Ora J, Matera MG. Olodaterol + tiotropium bromide for the treatment of chronic obstructive pulmonary disease. Expert Rev Clin Pharmacol. 2015;8(5):529-539.

15. Singh D, Ferguson GT, Bolitschek J, et al. Tiotropium + olodaterol shows clinically meaningful improvements in quality of life. Respir Med. 2015;109(10):1312-1319.
16. Beeh KM, Westerman J, Kirsten AM, et al. The 24-h lung-function profile of once-daily tiotropium and olodaterol fixed-dose combination in chronic obstructive pulmonary disease. Pulm Pharmacol Ther. 2015; 32:53-59.

17. Beeh KM, Derom E, Echave-Sustaeta J, et al. The lung function profile of once-daily tiotropium and olodaterol via Respimat ${ }^{\mathbb{}}$ is superior to that of twice-daily salmeterol and fluticasone propionate via Accuhaler $^{\circledR}$ (ENERGITO ${ }^{\circledR}$ study). Int J Chron Obstruct Pulmon Dis. 2016; 11:193-205.

18. Ferguson GT, Flezar M, Korn S, et al. Efficacy of tiotropium + olodaterol in patients with chronic obstructive pulmonary disease by initial disease severity and treatment intensity: a post hoc analysis. Adv Ther. 2015;32(6):523-536.

19. Sahoo U. Basic principles. In: Clinical Research in Asia: Opportunities and Challenges. Cambridge: Woodhead Publishing Ltd.; 2012:45-46.

20. Serebruany VL, Tomek A, Pya Y, Bekbossynova M, Kim MH. Inferiority of ticagrelor in the PHILO trial: play of chance in East Asians or nightmare confirmation of PLATO-USA? Int J Cardiol. 2016; 215:372-376.

21. Yano R, Konno A, Watanabe K, et al. Pharmacoethnicity of docetaxelinduced severe neutropenia: integrated analysis of published phase II and III trials. Int J Clin Oncol. 2013;18(1):96-104.

22. Huang CE, Lu CH, Chen PT, et al. Efficacy and safety of dose-modified docetaxel plus cisplatin-based induction chemotherapy in Asian patients with locally advanced head and neck cancer. J Clin Pharm Ther. 2012; 37(3):342-347.

23. Wang HM, Lin CY, Hsieh CH, et al. Induction chemotherapy with dosemodified docetaxel, cisplatin, and 5-fluorouracil in Asian patients with borderline resectable or unresectable head and neck cancer. $J$ Formos Med Assoc. 2017;116(3):185-189.

24. European Medicines Agency. ICH Topic E 11 Clinical Investigation of Medicinal Products in the Paediatric Population. Available: http://www.ema.europa.eu/docs/en_GB/document_library/Scientific_guideline/2009/09/WC500002926.pdf. Accessed September 12, 2016.

25. Yasuda SU, Zhang L, Huang SM. The role of ethnicity in variability in response to drugs: focus on clinical pharmacology studies. Clin Pharmacol Ther. 2008;84(3):417-423.

26. Ng M, Freeman MK, Fleming TD, et al. Smoking prevalence and cigarette consumption in 187 countries, 1980-2012. JAMA. 2014;311(2): 183-192.

27. Jones PW, Anderson JA, Calverley PM, et al. Health status in the TORCH study of COPD: treatment efficacy and other determinants of change. Respir Res. 2011;12(1):71.

28. Boehringer Ingelheim International $\mathrm{GmbH}$. Spiolto Respimat 2.5 microgram $/ 2.5$ microgram, inhalation solution. Summary of product characteristics, labelling and package leaflet 2015. Available from: http://mri.medagencies.org/download/NL_H_3157_001_FinalPI.pdf. Accessed March 1, 2016.

29. Tang Y, Massey D, Zhong NS. Evaluation of the efficacy and safety of tiotropium bromide (5 microg) inhaled via Respimat in Chinese patients with chronic obstructive pulmonary disease. Chin Med J (Engl). 2013; 126(19):3603-3607.

30. Decramer M, Janssens W. Chronic obstructive pulmonary disease and comorbidities. Lancet Respir Med. 2013;1(1):73-83.

31. Negewo NA, Gibson PG, McDonald VM. COPD and its comorbidities: impact, measurement and mechanisms. Respirology. 2015;20(8): $1160-1171$. 


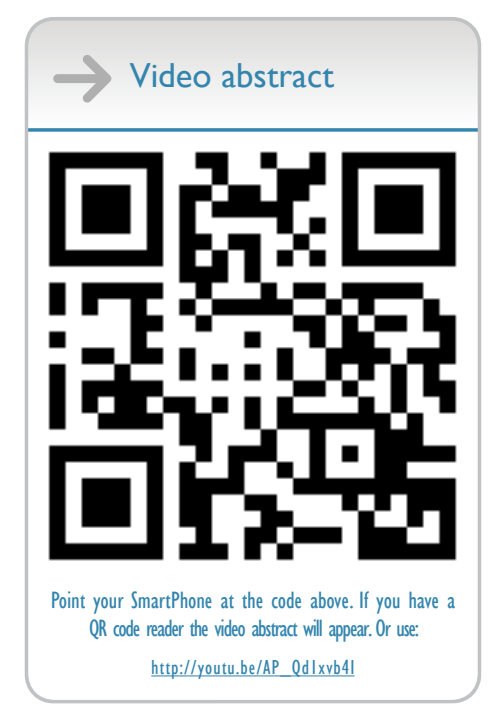

International Journal of COPD

Dovepress

\section{Publish your work in this journal}

The International Journal of COPD is an international, peer-reviewed journal of therapeutics and pharmacology focusing on concise rapid reporting of clinical studies and reviews in COPD. Special focus is given to the pathophysiological processes underlying the disease, intervention programs, patient focused education, and self management protocols.

This journal is indexed on PubMed Central, MedLine and CAS. The manuscript management system is completely online and includes a very quick and fair peer-review system, which is all easy to use. Visit $\mathrm{http}: / / \mathrm{www}$.dovepress.com/testimonials.php to read real quotes from published authors.

Submit your manuscript here: http://www.dovepress.com/international-journal-of-chronic-obstructive-pulmonary-disease-journal 